\title{
Filum terminale paraganglioma a diagnostic dilemmas- A case report
}

\author{
Mithilesh Kumar Pandey ${ }^{1}$, Debajit Ray Barman², Sibaji Dasgupta ${ }^{3}$, Kaushik Roy $^{4}$, Suniti Kumar Saha ${ }^{5}$ \\ ${ }^{1}$ Assistant Professor, Department of Neurosurgery, Government Medical College Haldwani, Nainital, ${ }^{2}$ R. M. O Cum Clinical Tutor, Department \\ of Neurosurgery Nil Ratan Sircar Medical College and Hospital, Kolkata, ${ }^{3}$ Post Graduate Trainee, Nil Ratan Sircar Medical College and \\ Hospital, Kolkata, ${ }^{4}$ Associate Professor, Department of Neurosurgery, Nil Ratan Sircar Medical College and Hospital, Kolkata, ${ }^{5}$ Professor, \\ Department of Neurosurgery, Nil Ratan Sircar Medical College and Hospital, Kolkata
}

\section{A B S T R A C T}

Filum terminale paraganglioma is a rare tumour with usual short segment spinal involvement (one or two segments) as described in various literatures. It can also present with long segment spinal involvement as in our case, the tumour has involved L4 to S1 segments. Prognosis of filum terminale paraganglioma is excellent after total excision as it is classified under WHO grade I tumor. Nonetheless, after subtotal removal, tumour recurrence can occur. Even such an extremely rare entity with a larger spectrum of presentation can be treated successfully by total removal of the tumour. Here we present a filum terminale paraganglioma which was diagnosed after histopathology and immuno-histochemistry. Patient made a full

Access this article online Website:

http://nepjol.info/index.php/AJMS DOI: 10.3126/ajms.v7i2.13324 E-ISSN: 2091-0576 P-ISSN: 2467-9100 recovery after tumour removal.

Key words: Paraganglioma, Filum Terminale, Cauda equina, Zell-ballen pattern

\section{INTRODUCTION}

Lerman was the first to coin the term paraganglioma of the cauda equina in 1972. Filum terminale paraganglioma are benign neuroectodermal tumours of the autonomic paraganglia, which usually originate from the chromaffin cells of neural crest cells. ${ }^{1}$

The first case of spinal paragangliomas was described by Miller and Torak who described it as a secretory ependymoma of filum terminale. Paragangliomas of central nervous system are rare $^{2}$ and majority present as spinal tumours usually located in the intradural, extramedullary compartment at the level of the cauda equina and the filum terminale, followed by thoracic and cervical regions. ${ }^{3,4}$

Low back pain is the main presenting symptom with the sciatica as well. ${ }^{1}$ Spinal paragangliomas are encountered in adolescents and adults, with peak incidence in the fifth decade. $^{5}$

Diagnosis is based on histopathology, immunohistochemistry and electron microscopy though the MRI is the investigation of choice. As they are included in WHO grade I tumor category, hence has good prognosis. Complete surgical excision is the treatment of choice and radiotherapy was reserved for locally invasive tumours. ${ }^{6}$

\section{CASE HISTORY}

A 26yr old male was presented with low back pain with bilateral L5 \& S1 radiculopathy with lower motor neuron bladder involvement for last 6 months. There were no signs or symptoms indicating catecholamine hyper-secretion, such as hypertension, psychomotor distress or headache. Both lower limb straight leg raising (SLR) test was positive without any other neurologic deficits.

MRI of lumbosacral region revealed a large lobulated altered signal intensity enhancing intraspinal intradural extramedullary space occupying lesion at the level of L4 to S1 measuring $70 \mathrm{~mm} \times 37 \mathrm{~mm} \times 24 \mathrm{~mm}$ in size (Figure1 $(\mathrm{a}-\mathrm{d})$ ). There was widening of spinal canal \& scalloping of posterior cortex of L5 \& S1 vertebral bodies. A provisional diagnosis of myxopapillary ependymoma was made. 


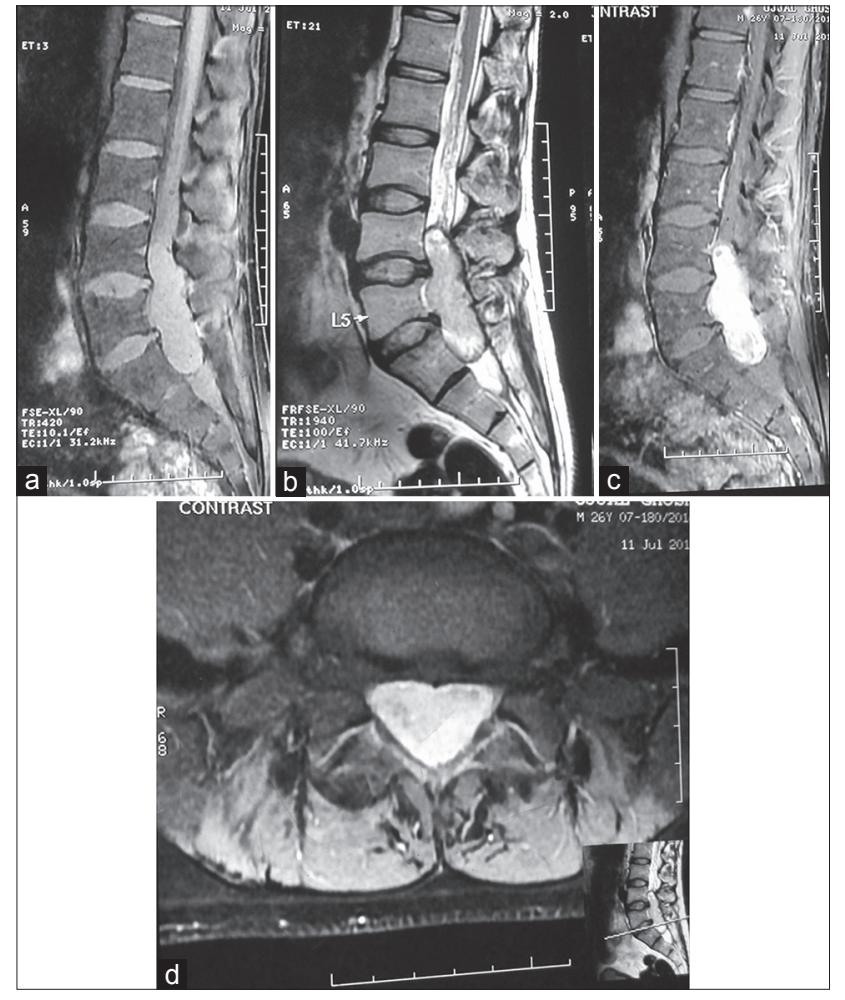

Figure 1: (a) Sagittal T1W MRI was reveals an isointense intraspinal intradural tumour extending from L4 to $S 1$, (b) In sagittal T2W MRI the lesion was mixed intensity more of hyperintense, (c) On sagittal T1W MRI with gadolinium, the tumor was brilliantly contrast enhancing, (d) On axial T1W MRI with gadolinium, the tumor was occupied whole of intraspinal space.

Routine blood investigation, X-ray chest PA view, USG abdomen was normal. Enblock excision of the tumor was done after dissecting the filum terminale cranial to the lesion and from the caudal roots. There was no evidence of infiltration of the caudal roots. An elongated, well encapsulated, cherry red highly vascular tumor was encompassing the cauda equina nerve roots and filum terminale.

The histopathology was reported as paraganglioma (Figure $2 \mathrm{a}$ and $2 \mathrm{~b}$ ). Immuno-histochemical testing was gave confirmatory dignosis as positive reaction for chromogranin A (Figure 2c) and synaptophysin.

\section{DISCUSSION}

The extra adrenal paragangliomas in the central nervous system usually observed in the carotid body, glomus jugulare and some others unusual sites are pineal region, sella turcica, suprasellar region or the orbit. ${ }^{1}$ The spinal localization is uncommon, with an incidence in the general population calculated at 0.07 per 100000 inhabitants. $^{7}$

Tumours affecting the carotid body and glomus region are usually parasympathetic whereas the spinal varieties

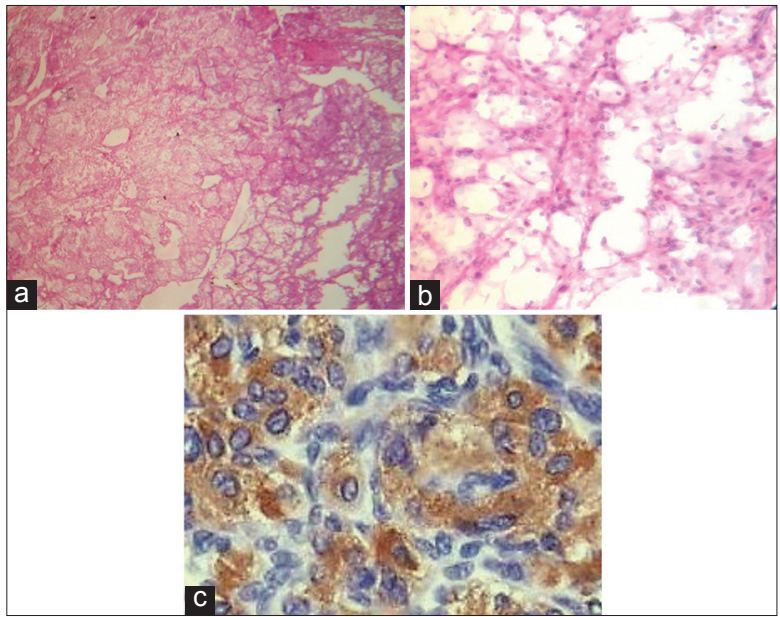

Figure 2: (a) Hematoxylin-eosin [ $\times 100]$ stained was showed zellballen pattern as the tumor tissue arranged in typical nests and lobules surrounded by many capillaries, (b) Hematoxylin-eosin $[\times 400]$ individual cells are round to polygonal with abundant eosinophilic cytoplasm and centrally placed nuclei with stippled chromatin, (c) Immunostain $[\times 400]$ photomicrograph is showing diffuse positivity of tumour cells for chromogranin $\mathrm{A}$

are typically sympathetic. They are believed to arise from sympathetic neurons which originate in the lateral horn of the spinal cord and follow the course of the nerve roots. ${ }^{1,7}$

Biologically, these lesions are generally benign. A genetic basis has been suggested on the strength of observations of familiarity and an association with leiomyosarcoma, chordoma or pituitary adenoma. ${ }^{7}$

Regarding their onset, the mean patient age is 46 years and clinical presentation usually consists of low back pain, sometimes associated with radicular pain. Caudaequina syndrome is unusual, despite the fact that the tumour takes up the whole diameter of the spinal canal. Sensory and motor deficits are also uncommon and in continence is relatively rare. ${ }^{7} 8$ The features of the our case was matching with the literatures in that the patient had a 6-month history of worsening low back pain and radicular pain. But contrary to published data here in this case the bladder and bowel involvement was present.

Despite their neuro endocrine origin, these tumours only rarely have functional hormonal activity. ${ }^{1}$

An MRI feature of spinal paragangliomas includes an isointense appearance, on T1-weighted images, and hyperintense on T2-weighted sequences with enhancement after gadolinium administration. These features are common to other intradural lesions, such as schwannomas, mixopapillary ependymomas, ependymomas, meningiomas, metastatic tumours and dermoid tumours or lipomas. ${ }^{8}$ 
In the diagnostic work-up of paraganglioma, two observations may be helpful for differentiation ${ }^{7,8}$

(1) A defect in the serpiginous structure between the conus and the lesion, suggesting dilatation of the serpentine vessels, which is uncommon in schwannomas and ependymomas.

(2) A hypointense appearance of the tumour rim on T2weighted sequences, suggesting para-magnetic effects caused by hemosiderin, which is typical of vascular tumours.

Histopathological diagnosis is based on the characteristics typical of paraganglioma, namely an organoid or "Zellballen"organization of argyrophilic cells which are circumscribed by vascular stroma, immunohistochemical testing with a positive reaction for chromogranine and sustentacular cell immune reaction for S100 protein. ${ }^{1}$

The majority of paragangliomas of cauda equina are amenable to surgery and total excision should be done. Surgery should be done without intra tumoural decompression to avoid troublesome bleeding. ${ }^{7}$ Radiotherapy is reserved for locally invasive tumours or where excision has been incomplete. In our case the complete excision of the tumour was done and hence radiotherapy was not given.

After gross excision prognosis is good. Only 4\% of spinal paragangliomas recur after gross total excision. ${ }^{6}$ As far as chemotherapy is concerned, at the time being it does not appear to play a role in the management of these lesions. The median free interval between surgical removal and local recurrence is estimated to be approximately 6 years. ${ }^{10}$

However, the fact that isolated cases of recurrence have been observed as many as 20 years after surgical treatment indicates that an assiduous long-term follow-up is mandatory whenever complete removal has not been achieved. ${ }^{7,10}$

\section{CONCLUSION}

The cauda equina paragangliomas are rare benign neoplasms. It usually presents with low backpain and radicular pain. MRI with contrast study gives useful information for surgical planning but is not diagnostic. The definitive diagnosis is only possible with histopathology, immunohistochemistry. Complete surgical resection is the treatment goal but long term follow-up required where complete excision of tumor was not possible.

\section{ACKNOWLEDGEMENT}

Very much thanks to Prof. Parimal tripathy and Prof. Subhasis Ghosh for his valuable suggestions in making this manuscript.

\section{REFERENCES}

1. Yang SY, Jin YJ, Park SH, Jahng TA, Kim HJ and Chung CK. Paragangliomas in the cauda equina region: Clinicopathoradiologic findings in four cases. J Neurooncol 2005; 72: 49-55.

2. Conti P, Mouchaty H, Spacca B, Buccoliero AM and Conti R. Thoracic extradural paragangliomas: a case report and review of the literature. Spinal Cord 2006; 44:120-125.

3. Fangtham M. Paraganglioma of thoracic spine: a case report. Asian Biomedicine 2008; 2: 503-506

4. Hong JY, Hur CY, Modi HN, Suh SW and Chang HY. Paraganglioma in the cauda equina. A case report. Acta Orthop Belg 2012; 78: 418-423.

5. Yoshida A, Umekita $\mathrm{Y}$, Ohi $\mathrm{Y}$, Hatanaka $\mathrm{S}$ and Yoshida H. Paraganglioma of the cauda equina. A case report and review of the literature.Acta Pathol Jpn 1991; 41: 305-310.

6. Rumana $\mathrm{M}$, Khursheed $\mathrm{N}$ and Vani $\mathrm{S}$. Primary spinal paragangliomas: A review. Neurosurgery Quarterly 2009; 19:196-199.

7. Landi A, Tarantino R, Marotta N, Rocco P, Antonelli M, Salvati M, et al. Paraganglioma of the filum terminale: case report. World Journal of Surgical Oncology 2009; 7:95.

8. Boncoeur-Martel MP, Lesort A, Moreau JJ, Labrousse F, Roche I, Bouillet $\mathrm{P}$, et al. MRI of paraganglioma of the filum terminale. $\mathrm{J}$ comput Assist Tomogr 1996; 20:162-165.

9. Djindjian $\mathrm{M}$, Ayache $\mathrm{P}$, Brugieres $\mathrm{P}$, Malapert $\mathrm{D}$, Baudrimont $\mathrm{M}$ and Poirier J. Giant gangliocytic paraganglioma of the filum terminal Case report. J Neurosurg 1990; 73: 459-461.

10. Say CC, Hori J and Spratt J. Chemodectoma with distant metastases: case report and review of literature. Am Surg1973; 39:333-341.

\section{Authors Contribution:}

MKP-Designed the study, analysed the data, drafted manuscript, and reviewed the manuscript, guarantor; DRB- Reviewed the manuscript, literature search, clinical studies; SD- Manuscript editing, literature search, manuscript preparation; KR- Contributed to the study design, manuscript editing, manuscript preparation; SKS- Concept, design, reviewed the manuscript.

Source of Support: Nil, Conflict of Interest: None. 